\title{
Leveraging a matrix of stakeholders to facilitate access to chemotherapy for women's cancers in the Democratic Republic of the Congo
}

\author{
Tankoy Gombo YouYou' ${ }^{1}$, Kabongo Mukuta Mathieu ${ }^{1}$, Michael L Hicks 2,3,4,5,6,a (iD, Ronda Henry-Tillman 7,b (iD, Alex Mutombo ${ }^{1}$, \\ Mukanya Mpalata Anaclet ${ }^{1}$, Mulumba Kapuku Sylvain ${ }^{1}$, Maya M Hicks ${ }^{8, c}$ (iD, Leeya Pinder,9,d (D), Louis Kanda ${ }^{10}$, Mirielle Kanda ${ }^{10}$ and \\ Groesbeck P Parham ${ }^{2,3, e}$ iD
}

\begin{abstract}
${ }^{1}$ Biamba Marie Mutombo Hospital, No. 9777, Boulevard Lumumba, Commune de Masina, Kinshasa, Democratic Republic of the Congo ${ }^{2}$ Department of Obstetrics and Gynecology, University of North Carolina at Chapel Hill, 101 Manning Dr, Chapel Hill, NC 27514, USA ${ }^{3}$ Department of Obstetrics and Gynecology, University Teaching Hospital - Women and Newborn Hospital, 10101 Nationalist Way, Lusaka, Zambia ${ }^{4}$ St Mary Mercy Cancer Center 36475 Five Mile Rd, Livonia, MI 48154, USA

${ }^{5}$ St Joseph Mercy Oakland Cancer Center 44405 Woodward Ave, Suite 202, Pontiac, MI 48324, USA

${ }^{6}$ McLaren Macomb Medical Center, 1000 Harrington Blvd, Mount Clemens, MI 48043, USA

${ }^{7}$ Winthrop P Rockefeller Cancer Institute, University of Arkansas for Medical Sciences, 4301 West Markham, Slot \#725, Little Rock, AR 72205, USAA

${ }^{8}$ Howard University College of Medicine, 520 W St NW, Washington, DC 20059, USA

9Department of Oncology, University of Washington, 1959 NE Pacific St, Seattle, Washington, DC 98195, USA

${ }^{10}$ Dikembe Mutombo Foundation, 400 Interstate N Pkwy, Suite 1040, Atlanta, GA 30339, USA

ahttps://orcid.org/0000-0002-1819-155X

bhttps://orcid.org/0000-0002-1782-9523

chttps://orcid.org/0000-0002-1993-3367

dhttps://orcid.org/ 0000-0002-8929-7810

dhttps://orcid.org/0000-0001-5922-5990
\end{abstract}

\section{Abstract}

Background: Cancer incidence is increasing worldwide. Over the next 20 years, the growing proportion of cases in low- and middle-income countries (LMICs) will account for an estimated $70 \%$ of all cancers diagnosed. The vast majority of cancer patients in LMICs will require chemotherapy, due to the advanced stage of their disease at the time of initial presentation. Unfortunately, the availability of cancer drugs in these environments is sparse, resulting in premature death and years of life lost. In an effort to lay a foundation for women's cancer control in the Democratic Republic of the Congo (DRC), we implemented a programme which combined workforce development, infrastructure creation and cancer drug access. This manuscript reports on our experience with the latter.

Methods: A private sector healthcare facility was selected as the programme implementation site. Workforce capacity was developed through a south-south partnership with an African national cancer centre. Cancer drugs were procured through a global cancer medicine access initiative.

Results: A new chemotherapy infusion unit was successfully established the Biamba Marie Mutombo Hospital in Kinshasa, DRC. A team of Congolese healthcare providers was trained at the Cancer Disease Hospital in Zambia to safely and effectively administer chemotherapy for breast and cervical cancer. Over 100 breast and cervical cancer patients have been treated with 337 courses of chemotherapy, without any serious adverse events.

Correspondence to: Groesbeck Preer Parham Email: professorparham@gmail.com

ecancer 2021, 15:1234

https://doi.org/10.3332/ecancer.2021.1234

Published: $13 / 05 / 2021$

Received: 18/11/2020

Publication costs for this article were supported by ecancer (UK Charity number 1176307).

Copyright: (C) the authors; licensee ecancermedicalscience. This is an Open Access article distributed under the terms of the Creative Commons Attribution License (http:// creativecommons.org/licenses/by/3.0), which permits unrestricted use, distribution, and reproduction in any medium, provided the original work is properly cited. 
Conclusion: Common barriers to cancer drug access and its administration can be eliminated using regional educational resources to build oncologic workforce capacity, private sector healthcare facilities for infrastructure support and pharmaceutical consortiums to procure lowcost cancer medicines. By leveraging a matrix of global, regional and local stakeholders, the prevailing status quo of very limited access to chemotherapy for women's cancers was creatively disrupted in DRC, Africa's largest fragile, conflict and violence-affected country.

Keywords: chemotherapy, South-south collaboration, Bioventures global health, Democratic Republic of the Congo, cervical cancer, breast cancer, Dikembe Mutombo Foundation, Biamba Marie Mutombo Hospital, fragile, conflict and violence-affected country

\section{Introduction}

Cancer is on the rise in low- and middle-income countries (LMICs). It is predicted that without major interventions there will be a $70 \%$ increase in the disease burden by 2040 [1]. An estimated $60 \%$ of cancer cases and $75 \%$ of deaths will occur in LMICs [2]. In order to solve this looming public health crisis, the major pillars of cancer care-health promotion, vaccination, screening, early detection, diagnostics, treatment and palliation-must be implemented, widely disseminated and sustained, especially in low-resource settings where the disease burden is heaviest. Screening and early detection coupled with access to high-quality surgical, medical and radiation therapy have significantly improved disease outcomes in high-income countries [3]. Unfortunately, these services are extremely limited in LMICs, resulting in few opportunities for cure, shortened survival and little chance for palliation.

At the very core of the problem is a markedly insufficient cancer workforce (oncologists of all types, nurses with training in oncology, ancillary personnel, pathologists etc.), a weak diagnostic and therapeutic infrastructure, limited access to modern anti-cancer drugs and meagre health expenditure budgets [4-6], the latter often resulting in patients and their families bearing the burden of the high costs of diagnosis and treatment [7]. The number of oncologists in sub-Saharan Africa is scarce, [8] ranging from zero in countries like Lesotho, Benin, Gambia, South Sudan and Sierra Leone to only a handful in Malawi, Burkina Faso, Rwanda and Togo [9]. The average number of pathologists per capita in Africa is 1/1,000,000, in comparison to the ratio of 1/20,000 in the US and UK [10]. Basic infrastructure platforms (electricity, water, clinic space, operating theatres, equipment and supplies, reagents and ITC) are weak throughout sub-Saharan Africa; power and stock outages are not uncommon; and maintenance of equipment (CT scans, MRI machines, linear accelerators etc.) is minimal and unreliable, primarily because of the unaffordability of maintenance agreements [11].

Such is the case in the Democratic Republic of the Congo, a fragile, conflict and violence-affected nation whose population of 84 million people, $>70 \%$ of whom live on less than $\$ 1.90 /$ day, has no access to established cancer care facilities [12, 13]. Armed with previous experience in successfully establishing women's cancer care services in highly resource-constrained African environments [14-19], we set out to disrupt the prevailing status quo and establish women's cancer care services in a private sector healthcare facility (Biamba Marie Mutombo Hospital, BMMH) in the capital city of Kinshasa. Herein we describe the challenges and experiences of establishing the chemotherapy infusion unit. Other manuscripts in this series describe the overall effort as well as the specifics of establishing service platforms for cervical and breast cancer.

\section{Methods}

\section{Workforce capacity development}

\section{Short course in chemotherapy infusion}

The initial step in launching the chemotherapy infusion unit consisted of the education and certification of selected staff members from $\mathrm{BMMH}$ in the safe administration of cytotoxic chemotherapy agents. This included knowledge of the properties and classification of various drugs, their side effects, complications and safe administration, with an emphasis on the specific drugs used for breast and cervical cancer. To achieve this goal, an intense, hands-on, short course in chemotherapy administration was developed at Zambia's national cancer centre- 
Cancer Diseases Hospital-in Lusaka, tailored for BMMH healthcare professionals. Under this curriculum, two BMMH general physicians and three nurses were trained to safely and effectively administer chemotherapy for breast and cervical cancer, following strict protocols. Prior to the beginning of the course, a pre-test was administered to the trainees to determine their baseline knowledge, followed by a posttest to measure the degree of mastery of the information that was taught, for purposes of validation and certification. Financial support was provided by the Howard G. Buffett (HGB) Foundation for all aspects of the short course, inclusive of international and local transportation, housing, a stipend, training fees, books and supplies. The didactic portion of the curriculum covered the following topics: treatment indications; classification and properties of chemotherapy agents; safe storage; mixing, transporting and disposal; proper dosing and safe administration; toxicities and potential complications; and management of complications. Hands-on training consisted of side-by-side observation and participation with Zambian clinical oncologists as they determined types and dosages of chemotherapy, pharmacists as they prepared the drugs for administration and nurse oncologists as they infused the drugs. The trainees also attended daily clinical rounds where they observed patients who were experiencing various drug-related adverse events. The educational curriculum was informed by multiple standard guidelines, inclusive of the National Comprehensive Cancer Network Harmonised Guidelines for sub-Saharan Africa [20]. The following modifications were made to further contextualise the guidelines for the conditions and circumstances (e.g., lack of radiation therapy) in the DRC: breast ultrasound in lieu of mammography for initial work-up; tamoxifen hormonal therapy provided for all breast cancer patients, in light of the absence of knowledge of tumour receptor status and no access to aromatase inhibitors or targeted therapy.

\section{Safety protocols}

A critical component of the short course curriculum focused on safety and included the following topics:

1. Personnel exposure-aerosol droplet and powder; dermal, oral and inhalation; food and water supply;

2. Patient safety-proper dosing, mixing and administration to prevent errors in administration and extravasation of vesicants;

3. Community safety-proper disposal and incineration of hazardous chemicals, adequate bathroom facilities in the chemotherapy unit, safe transportation of chemotherapy drugs and hazards waste through the hospital and proper storage of chemotherapy agents;

4. Management of complications-spills, extravasations, neutropenia, anaemia, excessive nausea and vomiting and dehydration.

Trainees were required to attain an $80 \%$ pass rate on the post-test for successful completion of the course.

\section{Infrastructure development}

A previously unused room in the hospital was remodelled (painted, windows restructured to allow for ventilation etc.) and repurposed for chemotherapy infusion, including installation of an air conditioner, bathroom with toilets and sink for patients and a separate one for staff. A list of mandatory equipment and supplies was provided by the Cancer Diseases Hospital (CDH) staff in Zambia.

\section{Accessing cancer medicines}

BMMH's hospital and clinic records were used to predict the number of eligible breast and cervical cancer patients who would need drugs over the next 2 years. An agreement was made between the Dikembe Mutombo Foundation (DMF) and Bioventures Global Health (BVGH) [21] for the latter organisation to facilitate the acquisition of chemotherapy drugs through its African Access Initiative. BVGH facilitated purchase of the requested drugs from Novartis, a global healthcare company located in Switzerland, at an agreed upon price which included shipping to the DRC. Representatives from the two organisation (DMF and BMMH) worked together to attain approval of the Congolese government for importation of drugs into the country, and to ensure that the products shipped from Novartis cleared DRC customs without delay. Only agents approved by the United States Food and Drug Administration (USFDA) were accessed. BVGH communicated directly with Novartis, and DMF with DRC government officials and BMMH hospital administration. Product batches with at least 12 months of remaining shelf life were selected. Procurement documents (invoices and airway bills) were shared with the DMF at least 1 week prior to the anticipated arrival of products. Flights with arrival dates early in the week were selected to avoid storage of drugs in the airport over the weekend. 


\section{Results}

All Congolese trainees in the short course in Zambia were certified following passage of the post-test. Following educational activities in Zambia, the trainees returned to the DRC and organised the chemotherapy infusion unit at BMMH, under the virtual guidance and oversight of a clinical oncologist from the $\mathrm{CDH}$. Once established, an oncology staff nurse from $\mathrm{CDH}$ visited the chemotherapy infusion unit at $\mathrm{BMMH}$ and for five consecutive days mentored and monitored Congolese staff as they administered cytotoxic chemotherapy agents to breast and cervical cancer patients. On the first day, problems were noted with potential personnel exposure related to improper use of eye protection and gowns during the mixing of chemotherapy, which was immediately corrected by the on-site oncology nurse mentor. Twelve patients received intravenous cytotoxic chemotherapy agents during the week of observation by the newly trained staff with no complications. Nausea and vomiting were managed appropriately with anti-emetics. There were no reported severe cases of neutropenia, thrombocytopenia, dehydration or the need for interim hospitalisation. The final assessment of the visiting CDH oncology nurse was that the newly trained staff were able to effectively and safely administer the required cancer medicines with only minor adjustments and corrections. Following handson mentoring and monitoring, safety and drug protocol issues were evaluated on a weekly then monthly basis via virtual audits $x 6$ months that were attended by a clinical oncologist from the $\mathrm{CDH}$.

\section{Infrastructure development}

All equipment and supplies recommended by CDH staff were successfully purchased with funds from the HGB Foundation (Figure 1). While the furniture was purchased locally, the HEPA mixing hood, refrigerator and all PPE were purchased from the US, as there were no vendors for such in the DRC. The HEPA mixing hood was installed to ensure the safety of personnel during the preparation of cytotoxic agents. Proper transport and disposal bins were also purchased locally and used exclusively for chemotherapy to ensure environmental safety.

\section{Access to cancer medicines}

Cytotoxic chemotherapy for 500 courses/infusions of therapy for cervix cancer and 500 course/infusions for breast cancer were purchased. The average cost of infusion for chemotherapy at BMMH was $\$ 250-300 /$ patient.

\begin{tabular}{|l|}
\hline Remodelling of space for chemotherapy suite \\
\hline HEPA mixing hood \\
\hline Chemotherapy beds/chairs \\
\hline Refrigerator $\left(-20^{\circ} \mathrm{C}\right)$ \\
\hline Personal Protective Equipment \\
\hline IV Fluid, Tubing, Syringes, Needles and Tourniquets \\
\hline Spill Kits \\
\hline Chemotherapy drugs \\
\hline Antiemetic agents \\
\hline Chemotherapy transport and disposal bins \\
\hline Protocols for administration of all drugs \\
\hline Protocols for spills and extravasation \\
\hline Protocols for the management of complications-neutropenia, anaemia, excessive nausea and vomiting and dehydration \\
\hline
\end{tabular}

Figure. 1. Chemotherapy infusion unit-equipment, supplies and structural modifications. 


\section{Discussion}

The obstacles to cancer treatment in sub-Saharan Africa are severe and multifaceted in nature. In a large survey of 31 cancer centres in Africa, those surveyed expressed concerns over the limited access to taxane chemotherapy and aromatase inhibitors, the absence of access to targeted therapy, the unavailability of radiation therapy and a lack of in-house pathology services [22]. Others have cited the lack of oncologic surgical capacity $[8,23]$.

To our knowledge, there were no clinical or medical oncologists within the country during the time of our training activities and programme implementation. This challenge alone can be a major limiting factor in establishing chemotherapy infusion services in LMICs. To overcome this barrier, we task-shifted the responsibilities of chemotherapy infusion to general physicians and nurses. This was facilitated using an abbreviated training course in chemotherapy infusion and a combination of virtual and hands-on mentoring and monitoring. Expert support for these activities was provided through a south-south collaboration with an established national cancer centre in the region.

Safety was of paramount importance during programme implementation and ongoing service provision. This was initially addressed through the short course curriculum. In addition, opportunities were created for an experienced oncology nurse from Zambia to be physically present in the newly established chemotherapy infusion unit in the DRC during start-up, and continued virtual monitoring thereafter. This allowed for close observation and immediate correction of any safety breeches. For further assurance, BMMH administration earmarked dedicated spaces for the warehousing, mixing and infusion of drugs and proper equipment, including personal protective equipment, biologic storage cabinets, biohazard transport and disposable bins.

To overcome the hurdles of hyperinflated prices for chemotherapeutic agents of unverifiable quality, we forged a relationship with BVGH through their African Access Initiative [21]. This allowed us to purchase drugs at reduced prices, thereby avoiding the excessively priced cancer medicines sold by private vendors in Kinshasa (3-5x's the international price) and ensuring their quality as they were certified by the US Federal Drug Administration.

A previous attempt to build capacity for chemotherapy services in Africa through south-south collaborations involved the Ugandan Cancer Institute and the eSwatini Ministry of Health [24]. The goal was to establish a chemotherapy unit in eSwatini by training healthcare providers from eSwatini in Uganda. Unlike in our collaboration, there was no mention of certification and the training experience in Uganda was described as an observership programme, in contrast to ours which included hands-on training. Details of the challenges encountered, onsite mentoring and monitoring activities in Swaziland, construction of a chemotherapy infusion facility, how chemotherapy was accessed and establishment of safety standards were not mentioned.

\section{Limitations}

A distinct obstacle that we initially encountered with this venture was the language barrier. The trainees were from a French-speaking African country, while the mentors were from the English-speaking nation of Zambia. All of the training material was initially written in English. We were able to overcome this barrier through translation of the written material into French and learning each other's languages to the extent where basic ideas and concepts could be communicated. We feel this is a very important factor to report because language and ethnography might influence the inclusion of training candidates from non-English speaking countries.

The World Health Organisation has an Essential Medicines List that contains several chemotherapeutic and palliative agents used in the treatment and palliation of breast and cervical cancer. Other than tamoxifen, these medicines are difficult to acquire or are unaffordable for governments or patients in many sub-Saharan African countries. Purchasing chemotherapy, even at low cost, inevitably leads to resource limitations. However, if properly managed, it can be creatively leveraged to generate profit that can then be used to support future purchases. 


\section{Conclusion}

In June 2019, a chemotherapy unit was established at the Biamba Marie Mutombo Hospital in Kinshasa, DRC, in support of a broader effort to provide access to women's cancer services. We leveraged the expertise of an established African cancer centre (Cancer Diseases Hospital of Zambia) to help train the local workforce, provide logistical guidance and oversight. Targeted investments in equipment and supplies along with modifications of pre-existing space inside a private sector hospital were used to create the necessary clinical infrastructure. Acquisition of high-quality chemotherapeutic agents at a reduced cost was facilitated through a novel global pharmaceutical consortium.

South-south collaborations are critical to building cancer care capacity in LMICs, as they can avoid some of the time-consuming and often wasteful missteps of north-south partnerships that may erroneously attempt to retrofit approaches that are not contextually appropriate for resource-constrained settings. Countries do not have to wait until all the pillars of cancer care-health promotion, prevention, detection, treatment and palliation-are adequately developed before sharing expertise. Instead, those that may have strengths in one particular area (e.g., surgical oncology) can share that expertise with another country in the region that has matched weaknesses. These partnerships can and should be designed, initiated, managed and controlled by leaders in the respective countries, to help ensure their relevance and impact.

\section{Abbreviations}

$\begin{array}{ll}\text { BMMH } & \text { Biamba Marie Mutombo Hospital } \\ \text { BVGH } & \text { Bioventures for Global Health } \\ \text { HGB } & \text { Howard G. Buffett Foundation } \\ \text { CDH } & \text { Cancer Diseases Hospital } \\ \text { DMF } & \text { Dikembe Mutombo Foundation } \\ \text { DRC } & \text { Democratic Republic of the Congo }\end{array}$

\section{Conflicts of interest}

None of the authors declare any conflicts of interest.

\section{Acknowledgments}

The authors acknowledge:

- Dikembe Mutombo Foundation

- Friends of Africa, Inc.

- Nurses and oncologists: University of Zambia and Cancer Diseases Hospital, Zambia

- Administration and clinical staff: Biamba Marie Mutombo Hospital

- BIO Ventures Global Health

\section{Funding statement}

Funding for the initiative was provided by a generous grant from the Howard G. Buffett Foundation whose mission is to catalyse transformational change to improve the standard of living and quality of life, particularly for the world's most impoverished and marginalised populations. 


\section{References}

1. Global Cancer Observatory [https://gco.iarc.fr/] Date accessed: 20/09/20

2. GLOBOCAN (2018) Counting the toll of cancer Lancet 392985 https://doi.org/10.1016/S0140-6736(18)32252-9

3. Allemani C, Matsuda T, and Carlo VD, et al (2018) Global surveillance of trends in cancer survival 2000-14 (CONCORD-3): analysis of individual records for 37513025 patients diagnosed with one of 18 cancers from 322 population-based registries in 71 countries Lancet 391(10125) 1023-1075 https://doi.org/10.1016/S0140-6736(17)33326-3 PMID: 29395269 PMCID: 5879496

4. Stefan DC (2015) Cancer care in Africa: an overview of resources J Glob Oncol 1(1) 30-36 https://doi.org/10.1200/JG0.2015.000406 PMID: 28804769 PMCID: 5551648

5. Boyle P, Ngoma T, and Sullivan R, et al (2019) Cancer in Africa: the way forward Ecancermedicalscience 13953 PMID: 31552126 PMCID: $\underline{6722114}$

6. Cancer-a neglected health problem in developing countries [http://www.inctr.org/about-inctr/cancer-in-developing-countries/] Date accessed: $1 / 12 / 20$

7. Gopal S, Wood WA, and Lee SJ, et al (2012) Meeting the challenge of hematologic malignancies in sub-Saharan Africa Blood 119 5078-5087 https://doi.org/10.1182/blood-2012-02-387092 PMID: 22461494 PMCID: 4507039

8. Vanderpuye V, Hammad N, and Martei Y, et al (2019) Cancer care workforce in Africa: perspectives from a global survey Infect Agent Cancer 1411 https://doi.org/10.1186/s13027-019-0227-8 PMID: 31139248 PMCID: 6528232

9. Mathew A (2018) Global survey of clinical oncology workforce J Glob Oncol 4 1-12.

10. Nelson AM, Milner DA, and Rebbeck TR, et al (2016) Oncologic care and pathology resources in Africa: survey and recommendations J Clin Oncol 34(1) 20-26 https://doi.org/10.1200/JCO.2015.61.9767

11. Kenneth Fleming (2019) Pathology and cancer in Africa Ecancermedicalscience 13945 PMID: 31552118 PMCID: 6722111

12. Globocan [https://gco.iarc.fr/today/data/factsheets/populations/180-congo-democratic-republic-of-fact-sheets.pdf] Date accessed: $20 / 12 / 20$

13. National Plans [Internet] National Plans|ICCP Portal [http://www.iccp-portal.org/map] Date accessed: 20/12/20

14. Songiso M, Pinder LF, and Munalula J, et al (2020) Minimizing delays in the breast cancer pathway by integrating breast specialty care services at the primary health care level in Zambia JCO Glob Oncol 6 859-865 https://doi.org/10.1200/GO.20.00083 PMID: 32579485 PMCID: $\underline{7328108}$

15. Chinula L, Hicks M, and Chiudzu G, et al (2018) A tailored approach to building specialized surgical oncology capacity: early experiences and outcomes in Malawi Gynecol Oncol Rep 26 60-65 https://doi.org/10.1016/j.gore.2018.10.001 PMID: 30364674 PMCID: 6197742

16. Pinder LF, Nzayisenga JB, and Shibemba A, et al (2018) Demonstration of an algorithm to overcome health system-related barriers to timely diagnosis of breast diseases in rural Zambia PloS One 13(5) e0196985 https://doi.org/10.1371/journal.pone.0196985 PMID: 29746541 PMCID: $\underline{5945023}$

17. Mwanahamuntu MH, Sahasrabuddhe VV, and Pfaendler KS, et al (2009) Implementation of 'see-and-treat' cervical cancer prevention services linked to HIV care in Zambia AIDS 23(6) N1-N5 https://doi.org/10.1097/QAD.0b013e3283236e11 PMID: 19279439 PMCID: $\underline{2747794}$

18. Pinder LF, Henry-Tillman R, and Linyama D, et al (2017) Leverage of an existing cervical cancer prevention service platform to initiate breast cancer control services in Zambia: experiences and early outcomes J Glob Oncol 4 1-8 
19. Parham GP, Mwanahamuntu MH, and Kapambwe S, et al (2015) Population-level scale-up of cervical cancer prevention services in a low-resource setting: development, implementation, and evaluation of the cervical ancer prevention program in Zambia PloS One 10(4) e0122169 https://doi.org/10.1371/journal.pone.0122169 PMCID: 4401717

20. National Comprehensive Cancer Network [Internet] NCCN Harmonized Guidelines ${ }^{\mathrm{TM}}$.[https://www.nccn.org/harmonized/default.aspx] Date accessed: 20/12/20

21. African Access Initiative (AAI) (2020) Improving Cancer Care in Africa [Internet] BVGH [https://bvgh.org/african-access-initiative/] Date accessed: 20/12/20

22. Vanderpuye V, Olopade O, and Dezheng H (2017) Pilot survey of breast cancer management in sub-saharan Africa J Glob Oncol 3(3) 194-200 https://doi.org/10.1200/JGO.2016.004945 PMID: 28717760 PMCID: 5493219

23. Boyle P, Ngoma T, and Sullivan R, et al (2019) Cancer in Africa: the way forward Ecancermedicalscience 13953 https://doi.org/10.3332/ ecancer.2019.953 PMID: 31552126 PMCID: 6722114

24. Kiyange F, Walusansa V, and Mandosela G, et al (2018) The role of South-to-South partnerships in developing cancer services in Africa Orem J Glob Oncol 4(Supplement 2) 163s https://doi.org/10.1200/jgo.18.21200

25. WHO Model List Of Essential Medicines - 21st list 2019 